\title{
Organic-Inorganic Hybrid Materials: Layered Double Hydroxides and Cellulose Acetate Films as Phosphate
}

\section{Recovery}

Gustavo Franco de Castro ${ }^{1}$, Jader Alves Ferreira ${ }^{2}$, Denise Eulálio ${ }^{2}$, Allan Robledo Fialho e Moraes ${ }^{2}$, Vera Regina Leopoldo Constantino ${ }^{3}$, Frederico Garcia Pinto ${ }^{2}$, Roberto Ferreira Novais ${ }^{1}$ and Jairo Tronto ${ }^{2}$

1. Department of Soil, University of Viçosa, Av. Peter Henry Rolfs, Bulding Silvyo Starling Brandão, CEP 36570-000, Viçosa (MG), Brazil

2. Department of Chemistry, University of Viçosa, Rio Paranaiba Campus, Highway MG-230, KM 07, CEP 38810-000, Rio Paranaiba $(M G)$, Brazil

3. Department of Fundamental Chemistry, University of São Paulo, Av. Prof. Lineu Prestes, 748, CEP 05508-000, São Paulo (SP), Brazil

\begin{abstract}
With demand increasing for phosphate recovery, a considerable share of current research is dedicated to elaborate multifunctional materials. In this way, the objective of this work was to produce hybrid films from the combination of cellulose acetate (CA) biopolymer and magnesium and aluminium layered double hydroxides (LDHs) and investigate their performance for phosphate recovery. In this work, the following materials were prepared and characterized: LDH, calcinated LDH (LDH-c), CA film (CAF), CA film with LDH (CAF-LDH) and CA film with LDH-c (CAF-LDH-c). The produced materials were characterized by $\mathrm{X}$-ray diffraction, thermogravimetric analysis coupled with differential scanning calorimetry and mass spectrometry, attenuated total reflectance Fourier transform infrared spectroscopy and scanning electronic microscopy. The thickness, $\mathrm{H}_{2} \mathrm{O}$ absorption $\left(\mathrm{A}_{\mathrm{H}_{2} \mathrm{O}}\right)$, stability in $\mathrm{H}_{2} \mathrm{O}$ and phosphate adsorption of the produced films were evaluated. The adsorption capacity of films was compared to LDHs in powder form. The CAF-LDH and CAF-LDH-c increased film thickness, where CAF-LDH-c was thicker than CAF-LDH. CAF-LDH-c had higher $\mathrm{A}_{\mathrm{H}_{2} \mathrm{O}}$ than the other films, because of its increased thickness and mainly because of the $\mathrm{H}_{2} \mathrm{O}$ sorption process of these materials. $\mathrm{H}_{2} \mathrm{O}$ stability of $98.97 \%$ for CAF-LDH and $96.81 \%$ for CAF-LDH-c suggest the produced films can maintain their structural properties even after a long contact period with aqueous solutions. For the CAF-LDH-c, the maximum adsorption capacity of phosphate, according to the Langmuir-Freundlich model, was $6.98 \mathrm{mg} / \mathrm{g}$. The adsorption value suggests that this film can be used as an efficient phosphorus (P) adsorbent from wastewater or a eutrophicated source.
\end{abstract}

Key words: Cellulose acetate films, layered double hydroxides, phosphorous adsorption, phosphorous recovery.

\section{Introduction}

The phenomenon of phosphorus $(\mathrm{P})$ retention by soil is well known and widespread in the literature. It is a relevant factor for nutritional management and culture development. Originally, it was thought that this retention was favorable to the use of $\mathrm{P}$ by the plants, but there are processes that occur in the soil, such as the formation of non-labile $\mathrm{P}$, which may

Corresponding author: Gustavo Franco de Castro, Ph.D., research fields: soil and plant nutrition. make it unfeasible to absorb this nutrient [1].

$\mathrm{P}$, unlike other nutrients, remains in more stable forms in the soil, considerably minimizing its presence in solution (P-solution). It is important to emphasize that in more weathered soils, especially the Oxisols, which are rich in more crystalline minerals such as the oxyhydroxides of iron $(\mathrm{Fe})$ and aluminum $(\mathrm{Al})$, a greater restriction of this $\mathrm{P}$-solution is expected [1]. In these soils, in addition to the phenomenon of $\mathrm{P}$ adsorption caused by the $\mathrm{Fe}$ and $\mathrm{Al}$ oxyhydroxides, there is also a high $\mathrm{P}$ requirement to meet the soil 
demand as a competitive drain with the plant for this nutrient [2, 3]. The high $\mathrm{P}$ demand required by Oxisols to maintain agricultural production requires the application of phosphate fertilizers in high doses, increasing production costs [4]. Moreover, available $\mathrm{P}$ reserves are finite [3] and of poor quality. An option to solve the problem of $\mathrm{P}$ in the Oxisols would be the capture of $\mathrm{P}$ from wastewaters and its reuse in agriculture as fertilizer [4]. In this manner, the use of organic-inorganic hybrid materials has emerged as an interesting option to study $\mathrm{P}$ reuse in agriculture.

In this sense, organic polymers and inorganic materials have been combined into hybrid materials for use in basic and applied research. In these hybrid organic-inorganic materials, interactions among the parts with favorable combinations of amounts and dispersion, have produced compounds with unique chemical and physical attributes compared to isolated components [5-11]. According to Sanchez et al. [12], these hybrid materials represent not only a creative alternative for researching new materials, but also allow for innovative industrial applications.

Layered double hydroxides (LDHs), also known as hydrotalcite-like compounds, are intercalated compounds with hydrated anions inserted into the interlayer spaces. In order to understand the structure of LDHs, it is convenient to start from the brucite structure, a mineral composed of $\mathrm{Mg}(\mathrm{OH})_{2}$. In brucite, $\mathrm{Mg}^{2+}$ is located in the center of an octahedron with vertexes occupied by hydroxyl anions. The octahedrons share edges among them forming flat and neutral layers. The structure of LDHs is similar to that of brucite, but some divalent cations are isomorphically substituted by trivalent cations, forming positively loaded layers. For the system to maintain its electroneutrality, hydrated anions are inserted between the layers, which present controlled stacking. These materials have the general formula: $\left[\mathrm{M}^{2+}{ }_{(1-x)} \mathrm{M}^{3+}{ }_{x}(\mathrm{OH})_{2}\right]\left(\mathrm{A}^{n-}\right)_{x / n} \cdot z \mathrm{H}_{2} \mathrm{O}$, where $\mathrm{M}^{2+}$ is a bivalent metal ion (such as $\mathrm{Ca}^{2+}, \mathrm{Mg}^{2+}, \mathrm{Zn}^{2+}$ ); $\mathrm{M}^{3+}$ is a trivalent metal ion (such as $\mathrm{Fe}^{3+}, \mathrm{Al}^{3+}, \mathrm{Mn}^{3+}$ ) and $\mathrm{A}^{n-}$ is the interlayer anion. LDHs occur in nature as minerals or can be synthetized at relatively low cost in an environmentally friendly manner, characterized as green chemistry [9, 13-16]. The fine texture of LDHs can limit their applications. Thus, the possibility of forming hybrid materials between LDHs and polymers is an interesting option from a practical point of view, making them usable for multiple applications. In this sense, it is more feasible to mechanically immobilize LDH in a biodegradable, low-cost polymer film for the collection of wastewater $\mathrm{P}$ and its subsequent reuse in agriculture as fertilizer.

Cellulose acetate (CA) polymers are thermoplastic materials produced by esterification of cellulose materials such as recycled paper, cotton and wooden cellulose, among others. These materials are used as matrices to obtain a variety of products such as optical film, laminates, textile fibers and coatings for medications and foods [17]. There is a current line of research that evaluates the synthesis and characterization of products (for example, montmorillonite) based on $\mathrm{CA}$ and clay minerals [17-20].

Until the present moment there are no works reported in the literature that use hybrid films containing $\mathrm{CA}$ and $\mathrm{LDH}$ as adsorbents for the uptake of P. In this way, the main objective of this work was to study $\mathrm{P}$ recovery, from aqueous solutions containing phosphate, using LDH (calcinated and non-calcinated) as adsorbents immobilized on $\mathrm{CA}$ films (CAFs).

\section{Materials and Methods}

All reagents used in this work presented an analytical purity level: $\mathrm{Mg}\left(\mathrm{NO}_{3}\right)_{2} \cdot 6 \mathrm{H}_{2} \mathrm{O}(99 \%)$ and $\mathrm{Al}\left(\mathrm{NO}_{3}\right)_{3} \cdot 9 \mathrm{H}_{2} \mathrm{O}$ (99\%) were obtained from Vetec, $\mathrm{Na}_{2} \mathrm{CO}_{3}(99.5 \%)$ and $\mathrm{KH}_{2} \mathrm{PO}_{4}(99 \%)$ from Dinâmica, $\mathrm{NaOH}(99 \%)$ from Merck, $\mathrm{HNO}_{3}$ (65\%) from Fmaia, acetone (PA) from Cromato Produtos Químicos and CA from Rhodia. Deionized water Milli- $Q^{\circledR}$ was used in all experiments. 


\subsection{Preparation of $\mathrm{LDH}$}

$\mathrm{LDH}$ containing magnesium $(\mathrm{Mg})$ and $\mathrm{Al}$ (molar ratio equal to two) intercalated with carbonate anions was prepared via the coprecipitation method at constant $\mathrm{pH}$ value. This method was choice because highly satisfactory results, obtaining MgAl-LDHs with good structural organization and phase purity. In this method, $500 \mathrm{~mL}$ of aqueous solution containing $0.2137 \mathrm{~mol} / \mathrm{L}$ of $\mathrm{Mg}\left(\mathrm{NO}_{3}\right)_{2} \cdot 6 \mathrm{H}_{2} \mathrm{O}$ and $0.0709 \mathrm{~mol} / \mathrm{L}$ of $\mathrm{Al}\left(\mathrm{NO}_{3}\right)_{3} \cdot 9 \mathrm{H}_{2} \mathrm{O}$ was added drop by drop to 2,500 $\mathrm{mL}$ of aqueous solution containing $0.056 \mathrm{~mol} / \mathrm{L}$ of $\mathrm{Na}_{2} \mathrm{CO}_{3}$ under constant stirring. During the synthetic step, aqueous solution containing $2.00 \mathrm{~mol} / \mathrm{L} \mathrm{NaOH}$ was added drop by drop to maintain a $\mathrm{pH}$ value of 10.0. After synthesis, the obtained solid material was separated by filtration and washed with water. The synthesized sample (abbreviated LDH) was dried in a desiccator in the presence of silica gel and under reduced pressure. The samples were macerated to obtain particles of uniform size.

\subsection{Preparation of Calcinated-LDH $(L D H-c)$}

The LDH sample obtained via the coprecipitation method as described above was subjected to the calcination process as follows: the powder was heated in a tubular furnace for $4 \mathrm{~h}$ at $550{ }^{\circ} \mathrm{C}$, under $\mathrm{O}_{2}$ atmosphere with a constant flow of $50 \mathrm{~mL} / \mathrm{min}$ and a heating rate of $10{ }^{\circ} \mathrm{C} / \mathrm{min}$. These conditions of calcination process were chosen to optimize the adsorption capacity of the calcined LDH by the strutural recovery property of this material [21, 22]. The calcined material (abbreviated LDH-c) was stored under reduced pressure in a desiccator containing silica gel.

\subsection{Preparation of CAF, CAF-LDH and CAF-LDH-c}

All films were prepared via the casting method using acetone as solvent. In this process, $3.00 \mathrm{~g}$ of CA was dissolved in $30 \mathrm{~mL}$ of acetone and allowed to stand for $24 \mathrm{~h}$ at room temperature. The resulting solution was spread on a flat glass surface and left to rest for the solvent to evaporate and form the CAF.
The CA solution in acetone was used to produce CAF. For this, $1.50 \mathrm{~g}$ of $\mathrm{LDH}$ (or $1.50 \mathrm{~g}$ of LDH-c) was added to the acetone solution and the mixture was stirred for $60 \mathrm{~min}$ with a magnetic stirrer at room temperature. Afterward, the suspension was applied on a flat glass surface and left to rest for $1 \mathrm{~h}$ for solvent evaporation. Hence, the mass ratio between $\mathrm{CA}$ and $\mathrm{LDH}$ (or LDH-c) was two. The produced films (CAF-LDH and CAF-LDH-c) were stored under reduced pressure in a desiccator containing silica gel.

\subsection{Characterization of the Produced Materials}

X-ray diffraction (XRD) analyses were performed in a Shimadzu XRD-6000 diffractometer, using a graphite crystal monochromator to select $\mathrm{Cu}-\mathrm{K} \alpha 1$ radiation with $\lambda=1.5406 \AA$ and a step away from $0.02^{\circ} / \mathrm{s}$, with $2 \theta$ angle between $4^{\circ}$ and $70^{\circ}$.

Thermal analyses were done on the TGA-DSC Netzsch analyzer STA 409 PC Luxx model coupled with the QMS 403 Aelos mass spectrometer, using an aluminum-oxide crucible, a heating rate of $10{ }^{\circ} \mathrm{C} / \mathrm{min}$ and a synthetic air flow rate of $50 \mathrm{~mL} / \mathrm{min}$. Samples were heated from $30{ }^{\circ} \mathrm{C}$ to $1,000{ }^{\circ} \mathrm{C}$.

For scanning electron microscopy (SEM) analyses, the samples were supported on conductive double sided adhesive tape and recovered with a thin gold film. Material morphologies were analyzed using a Zeiss EVO 50 scanning electron microscope.

The attenuated total reflectance Fourier transform infrared spectroscopy (ATR-FTIR) spectra were recorded with a Jasco spectrometer, model FT/IR-4100 in the range of 4,000 to $400 / \mathrm{cm}$, at $4 / \mathrm{cm}$ resolution and 256 scannings.

The thicknesses of the CAF, CAF-LDH and CAF-LDH-c films were determined with a digital micrometer, model ID-C112XB, Mitutoyo Corp, Japan. The average thickness value was calculated based on five measurements done at random points on each sample, according to Otoni et al. [23].

Water absorption $\left(\mathrm{A}_{\mathrm{H}_{2} \mathrm{O}}\right)$ of the films was determined according to methodology proposed by Espitia et al. [24]. Film samples (in triplicate) were 
dried in an oven at $105{ }^{\circ} \mathrm{C}$ for $24 \mathrm{~h}$ up to constant mass. Afterward, films were placed in beakers containing $50 \mathrm{~mL}$ of deionized $\mathrm{H}_{2} \mathrm{O}$ and kept at $25^{\circ} \mathrm{C}$ for $2 \mathrm{~h}$. The $\mathrm{A}_{\mathrm{H}_{2} \mathrm{O}}$ value was obtained from the relationship between the initial and swelled mass of the sample. Before measuring the swelled mass, excess water was carefully removed from the film surfaces with filter paper.

The stability of CAF-LDH and CAF-LDH-c were tested in water by adding $0.10 \mathrm{~g}$ of film to $10 \mathrm{~mL}$ of $\mathrm{H}_{2} \mathrm{O}$. The films were immersed in $\mathrm{H}_{2} \mathrm{O}$ and kept in a thermostatic bath at $30{ }^{\circ} \mathrm{C}$, under stirring in a closed environment. The samples were subjected to different stirring times (between $30 \mathrm{~min}$ and $24 \mathrm{~h}$ ). The experiments were performed in triplicate. After stirring, the quantities of $\mathrm{Mg}^{2+}$ and $\mathrm{Al}^{3+}$ ions lixiviated from the films to the solution were determined by atomic absorption spectrophotometry using the Varian spectrophotometer, model AA240FS. Film stability in water was calculated by comparing the initial quantities of $\mathrm{Mg}^{2+}$ and $\mathrm{Al}^{3+}$ ions in CAF-LDH and CAF-LDH-c films with the amounts of metal in the water solution after stirring after different stirring times.

The quantities of $\mathrm{Mg}^{2+}$ and $\mathrm{Al}^{3+}$ ions in the $\mathrm{LDH}$ and LDH-c samples were evaluated by atomic absorption spectrophotometry on a Varian spectrophotometer, model AA240FS, as follows: powdered samples were solubilized in $14.44 \mathrm{~mol} / \mathrm{L}$ of $\mathrm{HNO}_{3}$ solution using a 1:100 ratio of $\mathrm{LDH}$ :solution (mg:mL). To quantify the contents of $\mathrm{Mg}^{2+}$ and $\mathrm{Al}^{3+}$ in CAF-LDH and CAF-LDH-c, the films were dried in a drying oven at $105{ }^{\circ} \mathrm{C}$ for $24 \mathrm{~h}$ until reaching a constant weight. After the films presented constant weight, with the quantities of $\mathrm{Mg}^{2+}$ and $\mathrm{Al}^{3+}$ present in the films were estimated indirectly by means of the levels found in the LDH and LDH-c.

\subsection{Adsorption Isotherms}

The phosphate adsorption isotherms were evaluated for LDH, LDH-c, CAF, CAF-LDH and CAF-LDH-c. For this, $20 \mathrm{mg}$ of the produced materials were added to $10 \mathrm{~mL}$ of solutions containing different phosphate ions concentrations (from $10 \mathrm{mg} / \mathrm{L}$ to $1,000 \mathrm{mg} / \mathrm{L}$ ) [25, 26]. The suspensions were stirred for $24 \mathrm{~h}$ in a thermostatic bath at $30{ }^{\circ} \mathrm{C}$ and closed system. The quantities of $\mathrm{P}$ in solution (supernatant) were determinated after the stirring time and the amount of $\mathrm{P}$ adsorbed in each material was calculated according to Eq. (1):

$$
Q_{e}=\frac{V\left(C_{i}-C_{e}\right)}{m}
$$

where $Q_{e}$ is the amount of phosphate adsorbed by unit weight of adsorbent $(\mathrm{mg} / \mathrm{g}), V$ is the volume of phosphate solution added (L), $C_{i}$ is the initial concentration of phosphate solution added $(\mathrm{mg} / \mathrm{L}), C_{e}$ is the balanced concentration of adsorbate solution $(\mathrm{mg} / \mathrm{L})$ and $m$ is the adsorbent mass $(\mathrm{g})$.

The experimental data were analyzed according to the Langmuir [27], Freundlich [28] and Langmuir-Freundlich [29] models by means of Eqs. $(2-4)$ :

$$
\begin{gathered}
Q_{e}=\frac{Q_{m} K_{L} C_{e}}{1+K_{L} C_{e}} \\
Q_{e}=K_{F} C_{e}^{1 / n} \\
Q_{e}=\frac{Q_{m} K C_{e}^{1 / n}}{1+K C_{e}^{1 / n}}
\end{gathered}
$$

where $Q_{e}$ is the amount of phosphate adsorbed by unit weight of adsorbent mass $(\mathrm{mg} / \mathrm{g})$, in the equilibrium concentration of adsorbate in solution, $C_{e}(\mathrm{mg} / \mathrm{L}) ; K_{L}$ $(\mathrm{L} / \mathrm{mg}), K_{F}(\mathrm{~L} / \mathrm{g})^{n}$ and $K(\mathrm{~L} / \mathrm{mg})$ representing the constants of Langmuir, Freundlich and Langmuir-Freundlich. $Q_{m}$ is the maximum $\mathrm{P}$ adsorption capacity in $\mathrm{mg} / \mathrm{g}$ and $n$ (dimensionless) is the Freundlich linearity constant.

\section{Results and Discussion}

\subsection{Characterization of Materials}

The XRD patterns of LDH, LDH-c, CAF, CAF-LDH and CAF-LDH-c samples are presented in Fig. 1. For LDH, the diffractogram shows a characteristic profile of material with a hydrotalcite-like structure (Fig. 1a). The repetition of basal reflections (003) and (006) is related to the 
stacking of the layers. This diffraction is typical of compounds with structural organization and a purity phase. For this material, the basal spacing (distance between two adjacent layers) calculated by Bragg's equation $\left(n \lambda=2 d_{h k l} \operatorname{sen} \theta\right)$ was $7.75 \AA$. This value is expected for carbonate anions intercalated in to MgAl-LDH [14, 30, 31]. The LDH-c XRD (Fig. 1b) shows peaks referring to the presence of $\mathrm{MgO}$, as indicated in the figure. For this material, the calcination process at suitable temperature and atmosphere may give rise to the $\mathrm{MgO}$ crystalline phase and other amorphous phases, such as oxides and mixed oxihydroxides $[21,22]$. The diffractrogram of CAF (Fig. 1c) present two centered peaks semi-crystalline at $2 \theta$ equal to $10.1^{\circ}$ and $17.6^{\circ}$ [32]. XRD pattern of CAF-LDH (Fig. 1d) presents characteristics of the mixture between polymer and LDH. The diffractrogram of this film presents basal reflections (003) and (006) typical of LDH intercalated with carbonate anions, as previously shown (Fig. 1a), as well as peaks centered at $2 \theta$ equal to $10.1^{\circ}$ and $17.6^{\circ}$ referring to the presence of CA. The diffractrogram of CAF-LDH-c (Fig. 1e) presents a peak related to (111) plane of $\mathrm{MgO}$ and also a signal of very low intensity attributed to plane (003) of LDH. This peak probably occurs because of the intercalation of $\mathrm{CO}_{3}{ }^{2-}$ in the LDH-c present in the film, from the contamination of this material by $\mathrm{CO}_{2}$ present in the air. This CAF-LDH-c contamination occurs because of the handling of this material during the synthesis and analysis processes.

ATR-FTIR spectra of LDH, LDH-c, CAF, CAF-LDH and CAF-LDH-c are shown in Fig. 2. For LDH (Fig. 2a), the spectrum show a very broad band in the region between $3,600 / \mathrm{cm}$ and $3,000 / \mathrm{cm}$ assigned to the $\mathrm{OH}$ stretching of the $\mathrm{H}_{2} \mathrm{O}$ molecules, as well as the hydroxyl groups present in the inorganic layers [33]. The intense band around $1,650 / \mathrm{cm}$ is attributed to bending mode of $\mathrm{H}_{2} \mathrm{O}$ molecules. The bands at $1,360,850$ and $630 / \mathrm{cm}$ are associated to several vibrational modes of $\mathrm{CO}_{3}{ }^{2-}$ intercalated and absorbed anions [31, 34].

The ATR-FTIR spectrum of LDH-c is shown in Fig. 2b. For this material, it is possible to observe the presence of two bands located at $850 / \mathrm{cm}$ and $670 / \mathrm{cm}$, which are attributed to vibration modes of $\mathrm{Al}-\mathrm{O}$ and $\mathrm{Mg}-\mathrm{O}$ of $\mathrm{Mg}(\mathrm{Al}) \mathrm{O}$ [21, 22, 35]. The CAF, CAF-LDH and CAF-LDH-c spectra are shown in Figs. 2c-2e. The bands centered at $3,400 / \mathrm{cm}$ are assigned to the $\mathrm{OH}$-stretching of the $\mathrm{H}_{2} \mathrm{O}$ molecules, as well as the hydroxyl groups and the $\mathrm{H}_{2} \mathrm{O}$ molecules $[33,34,36]$. The band at $1,748 / \mathrm{cm}$ is typical of CA formation and is related to the stretching of $\mathrm{C}=\mathrm{O}$ groups [37]. Hanna et al. [38] and Barud et al. [36], observed the same carbonyl band at $1,754 / \mathrm{cm}$ and $1,755 / \mathrm{cm}$ for CA, respectively. The $1,237 / \mathrm{cm}$ band refers to the $\mathrm{C}-\mathrm{O}$ stretching of the acetyl group [36]. Brum et al. [37] observed the stretching of $\mathrm{C}-\mathrm{O}$ of the $\mathrm{O}-(\mathrm{C}=\mathrm{O})-\mathrm{CH}_{3}$ at $1,249 / \mathrm{cm}$ band. The presence of the band at $1,370 / \mathrm{cm}$ is related to $\mathrm{C}-\mathrm{H}$ bending $[39,40]$. The band at $1,037 / \mathrm{cm}$ is related to $\mathrm{C}-\mathrm{O}$ stretching [40].

The TGA-DTG-DSC and TGA-MS curves of LDH, CAF, CAF-LDH and CAF-LDH-c are shown in Fig. 3. The LDH, CAF-LDH and CAF-LDH-c curves (Figs. $3 \mathrm{a}, 3 \mathrm{e}$ and $3 \mathrm{~g}$ ) show two stages of thermal decomposition. The first stage occurs from $30{ }^{\circ} \mathrm{C}$ up to close to $200{ }^{\circ} \mathrm{C}$ and the second one from $200{ }^{\circ} \mathrm{C}$ up to $500{ }^{\circ} \mathrm{C}$. For CAF (Fig. 3c), the first stage of thermal decomposition occurs between $300{ }^{\circ} \mathrm{C}$ and $400{ }^{\circ} \mathrm{C}$, and the second one between $400{ }^{\circ} \mathrm{C}$ and $550{ }^{\circ} \mathrm{C}$. For CAF, Zhou et al. [41] and Dehkordi et al. [19] demonstrated the existence of a first stage of weight loss because of the evaporation of physically adsorbed $\mathrm{H}_{2} \mathrm{O}$. In this work, this thermal decomposition stage was not highlighted for CAF. Dehkordi et al. [19] attributed the CAF thermal decomposition stage starts at $367{ }^{\circ} \mathrm{C}$, with $\mathrm{CA}$ chain degradation, followed by primary decomposition of volatile and dehydrated compounds [41]. According to these authors, the thermal decomposition stage of CAF at $542{ }^{\circ} \mathrm{C}$ is attributed to the carbonization of the sample, with complete degradation and decomposition of the film. 


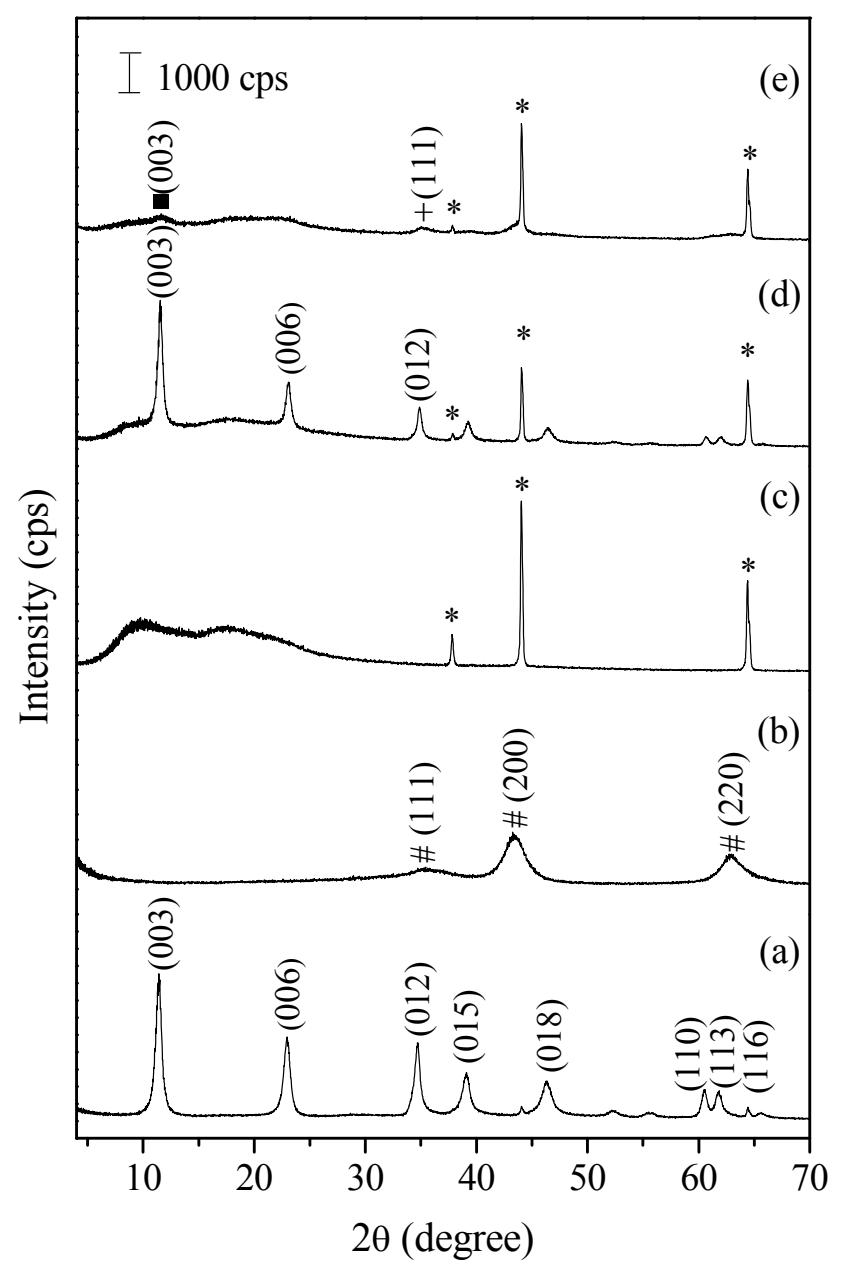

Fig. 1 X-ray diffraction (XRD) patterns of (a) layered double hydroxide (LDH); (b) calcinated LDH (LDH-c); (c) cellulose acetate film (CAF); (d) CAF-LDH; (e) CAF-LDH-c.

*: Al signal of the sample holder; +: MgO signal; $\mathbf{\square}$ : LDH signal; \#: peaks referring to the presence of $\mathrm{MgO}$.

The CAF-LDH and CAF-LDH-c presented low thermal stability in relation to CAF. The mass residue for CAF was $1.74 \%$, while for CAF-LDH and CAF-LDH-c, the residues were of $18.6 \%$ and $28.4 \%$. The mass residue in these materials corresponds to oxides and oxyhydroxides derived from $\mathrm{LDH}$ and LDH-c. The mass spectrum of LDH (Fig. 3b) indicates that $\mathrm{H}_{2} \mathrm{O}$ molecules are lost up to $200{ }^{\circ} \mathrm{C}$ $(m / z=18)$, adsorbed on the surface and intercalated between the layers. The second stage of thermal decomposition $(m / z=18)$ occurs between $200{ }^{\circ} \mathrm{C}$ and $500{ }^{\circ} \mathrm{C}$. In this temperature range, the dihydroxylation process of the layers occurs with the release of $\mathrm{H}_{2} \mathrm{O}$ $[22,42]$. It is also possible to verify the loss of $\mathrm{CO}_{2}$ $(m / z=44)$ from $\mathrm{CO}_{3}{ }^{2-}$ anions, intercalated between the layers. For CAF, CAF-LDH and CAF-LDH-c (Figs. $3 \mathrm{~d}, 3 \mathrm{f}$ and $3 \mathrm{~h}$ ), a small loss of $\mathrm{H}_{2} \mathrm{O}$ molecules occurs $(m / z=18)$ at $350{ }^{\circ} \mathrm{C}$. For CAF, there are two loss $\mathrm{CO}_{2}$ stages $(m / z=44)$ from the film at temperatures between $350{ }^{\circ} \mathrm{C}$ and $500{ }^{\circ} \mathrm{C}$.

The SEM representative images obtained by $\mathrm{LDH}$, LDH-c, CAF, CAF-LDH and CAF-LDH-c are shown in Fig. 4. LDH presented typical images of this type of material (Figs. $4 \mathrm{a}$ and 4b), with agglomerated particules shaped like hexagonal platelets forming a structure known as rose sand [43]. LDH-c shows regions with hexagonal platelet morphology and regions with desensely packed particles, as a result of 


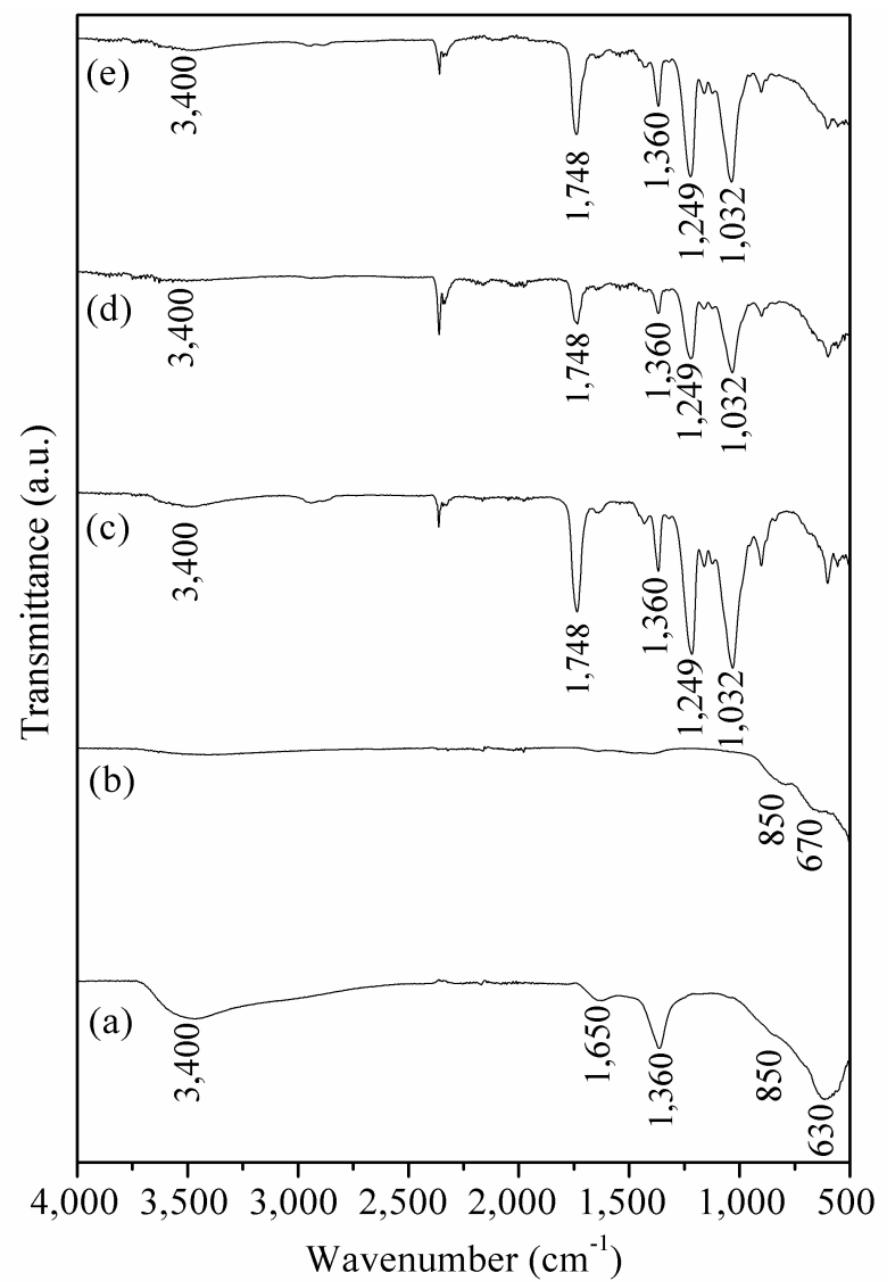

Fig. 2 Attenuated total reflectance Fourier transform infrared spectroscopy (ATR-FTIR) spectra of (a) LDH; (b) LDH-c; (c) CAF; (d) CAF-LDH; (e) CAF-LDH-c.

the thermal treatment applied (Figs. 4c and 4d). The LDH and LDH-c particles (Figs. 4a-4d) were also visualized in the images obtained from CAF-LDH and CAF-LDH-c (Figs. 4g-4j). The images show that LDH powders were uniformly spread on the polymeric film. Moreover, it was also observed in the hybrid film images the presence of regions with high numbers of pores (indicated by arrows). CAF images presented regions with a lot of uniformity, in addition to regions where the electron-beam decomposed the polymeric film (indicated with arrows). The produced hybrid materials presented more thermal stability than the pristine film.

The film thicknesses were modified by interactions between the polymers and LDHs (Table 1). The formation of hybrid materials, CAF-LDH and CAF-LDH-c, increased the film thickness. CAF-LDH-c had greater thickness than CAF-LDH. These variations can also influence the properties of these materials, such as $\mathrm{A}_{\mathrm{H}_{2} \mathrm{O}}$ [44].

$\mathrm{A}_{\mathrm{H}_{2} \mathrm{O}}$ has been described for several materials according to the Second Fick's Law. This law however is only applicable when: (i) the material is homogeneous, (ii) there is no chemical interaction between water and the material, (iii) the $\mathrm{H}_{2} \mathrm{O}$ sorption mechanism is only diffusion, (iv) there is no extraction of soluble materials and $(\mathrm{v})$ the material dimension does not change during $\mathrm{A}_{\mathrm{H}_{2} \mathrm{O}}$. Therefore, CA based materials cannot be evaluated in relation to $\mathrm{A}_{\mathrm{H}_{2} \mathrm{O}}$, according to the concepts of this law $[45,46]$. In 

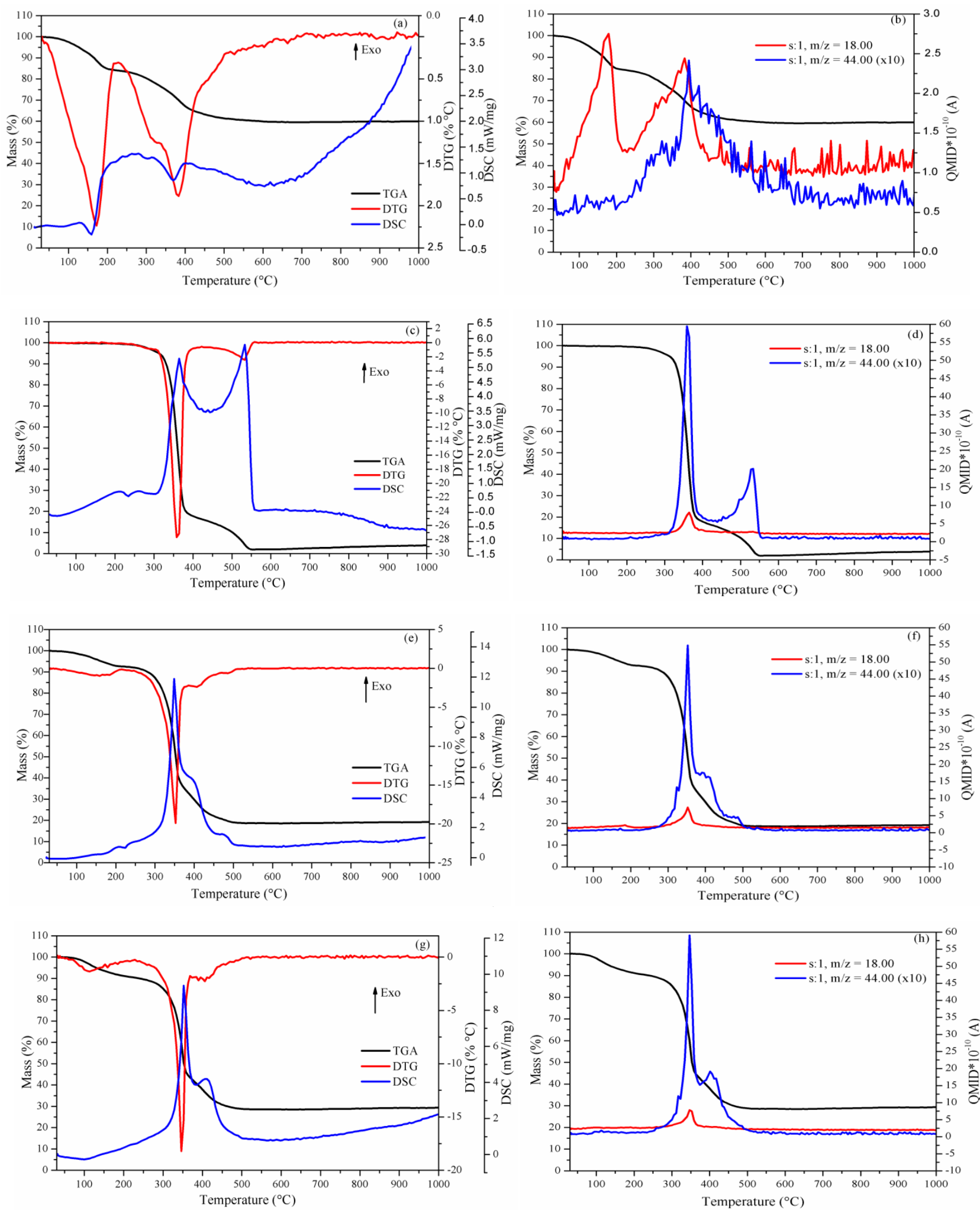

Fig. 3 (a) TGA-DSC LDH; (b) TGA-MS LDH; (c) TGA-DSC CAF; (d) TGA-MS CAF; (e) TGA-DSC CAF-LDH; (f) TGA-MS CAF-LDH; (g) TGA-DSC CAF-LDH-c; (h) TGA-MS CAF-LDH-c. 

Cellulose Acetate Films as Phosphate Recovery
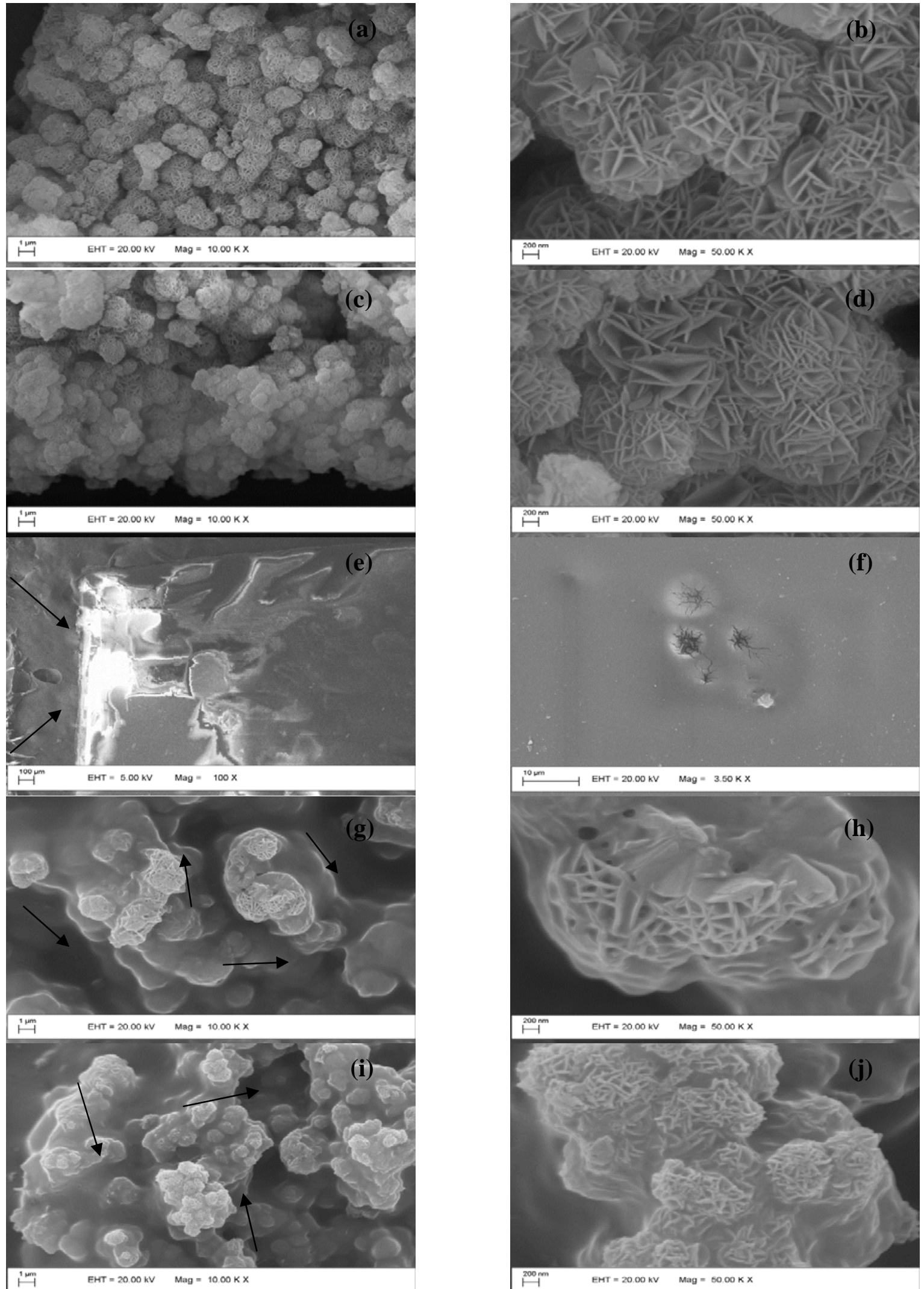

Fig. 4 Scanning electron microscopy (SEM) images obtained at different magnifications for (a) LDH; (b) LDH; (c) LDH-c; (d) LDH-c; (e) CAF; (f) CAF; (g) CAF-LDH; (h) CAF-LDH; (i) CAF-LDH-c; (j) CAF-LDH-c. 
Table 1, it was possible to observe a great difference in $\mathrm{A}_{\mathrm{H}_{2} \mathrm{O}}$ among the films produced. This absorption depends on the hydrophilicity and chemical nature of the materials [46] and also depends on the morphological structure. As such, the higher $\mathrm{A}_{\mathrm{H}_{2} \mathrm{O}}$ by CAF-LDH and CAF-LDH-c compared to CAF, can be attributed to their higher porosity and thickness as well as the higher hydrophilic character of LDHs present in these films. CAF-LDH-c showed $\mathrm{A}_{\mathrm{H}_{2} \mathrm{O}}$ higher than the other films, which occurs because of its higher thickness and mainly because of the $\mathrm{H}_{2} \mathrm{O}$ sorption process of these materials. This $\mathrm{H}_{2} \mathrm{O}$ sorption promotes the regeneration of lamellar structure, which some works describe as memory effect [47-49].

In addition to studying $\mathrm{A}_{\mathrm{H}_{2} \mathrm{O}}$ by films, it was also evaluated the stability. The concentrations of $\mathrm{Mg}^{2+}$ in solution, after $24 \mathrm{~h}$ of stirring in water, were 0.76 $\mathrm{mg} / \mathrm{g}$ for CAF-LDH and $3.31 \mathrm{mg} / \mathrm{g}$ for CAF-LDH-c (Fig. 5). Nevertheless, the concentrations of $\mathrm{Mg}^{2+}$ were $74.2 \mathrm{mg} / \mathrm{g}$ and $103.9 \mathrm{mg} / \mathrm{g}$ (Table 2) in CAF-LDH and CAF-LDH-c, respectively. Therefore, analyzing the initial amount of $\mathrm{Mg}^{2+}$ in these films and released in solution, the observed stability in $\mathrm{H}_{2} \mathrm{O}$ was $98.97 \%$ for CAF-LDH and $96.81 \%$ for CAF-LDH-c. These values suggest that the produced films can maintain their structural properties even after a long period of contact with aqueous solutions. The amount of $\mathrm{Al}^{3+}$ released in solution was at lower concentrations than the range of detection of the atomic absorption equipment ( $3 \mathrm{mg} / \mathrm{L}$ to $250 \mathrm{mg} / \mathrm{L})$;

Table 1 Thickness and $\mathrm{H}_{2} \mathrm{O}$ absorption $\left(\mathrm{A}_{\mathrm{H}_{2} \mathrm{O}}\right)$ by cellulose acetate film (CAF), CAF-layered double hydroxide (CAF-LDH) and CAF-calcinated LDH (CAF-LDH-c).

\begin{tabular}{lll}
\hline Material & Thickness $(\mu \mathrm{m})$ & $\mathrm{A}_{\mathrm{H}_{2} \mathrm{O}}(\%)$ \\
\hline CAF & $78.4 \pm 7.5$ & $13.2 \pm 0.9$ \\
CAF-LDH & $108.4 \pm 11.3$ & $17.2 \pm 0.6$ \\
CAF-LDH-c & $134.8 \pm 13.9$ & $32.8 \pm 1.2$ \\
\hline
\end{tabular}

Table 2 Total quantities of $\mathrm{Mg}^{2+}$ and $\mathrm{Al}^{3+}$ for $\mathrm{LDH}, \mathrm{LDH}-\mathrm{c}, \mathrm{CAF}-\mathrm{LDH}$ and CAF-LDH-c.

\begin{tabular}{llll}
\hline Sample & $\mathrm{Mg}^{2+}(\mathrm{mg} / \mathrm{g})$ & $\mathrm{Al}^{3+}(\mathrm{mg} / \mathrm{g})$ & $\mathrm{Mg}^{2+}: \mathrm{Al}^{3+}(\mathrm{m}: \mathrm{m})$ \\
\hline LDH & 236.6 & 70.2 & 3.37 \\
LDH-c & 322.1 & 99.5 & 3.24 \\
CAF-LDH & 74.2 & 22.0 & 3.37 \\
CAF-LDH-c & 103.9 & 32.1 & 3.24 \\
\hline
\end{tabular}

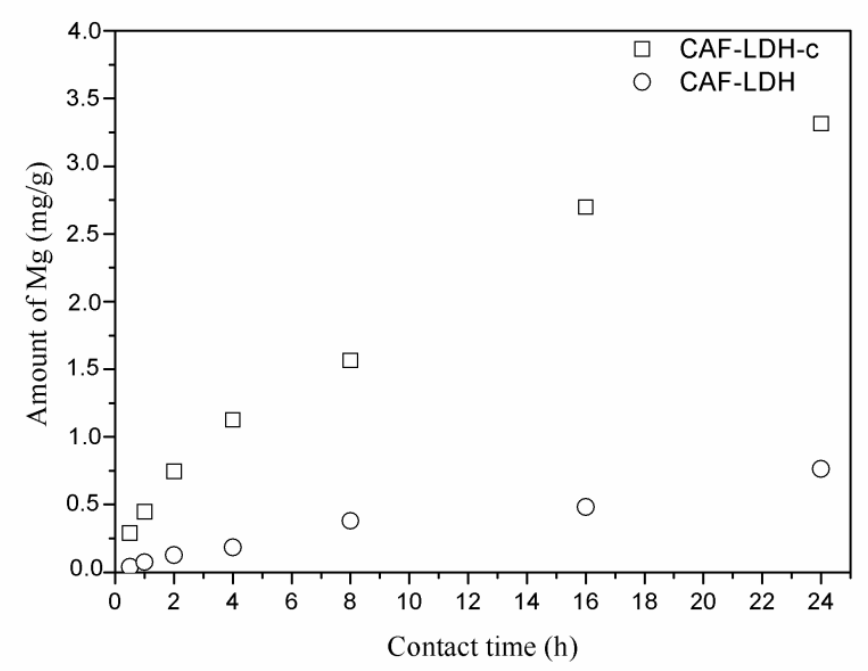

Fig. 5 Amount of $\mathrm{Mg}^{2+}$ in solution after different contact times of the films in water. 
therefore, they were not reported in this work.

\subsection{Adsorption Isotherms}

The $\mathrm{P}$ adsorption isotherms using $\mathrm{LDH}, \mathrm{LDH}-\mathrm{c}$, CAF, CAF-LDH and CAF-LDH-c as adsorbents were adjusted for the Langmuir, Freundlich and Langmuir-Freundlich models (Fig. 6). Langmuir's model assumes adsorption occurs in monolayer, on the uniform surface without interactions among adsorbed molecules, while Freundlich's model describes adsorption on non-uniform surface or heterogeneous sorption [29, 50]. Langmuir-Freundlich's model integrates the Langmuir and Freundlich models and considers the adsorption process to be controlled by multiple mechanisms [50] in heterogeneous surfaces [51]. The parameters of the proposed models are presented in Table 3.
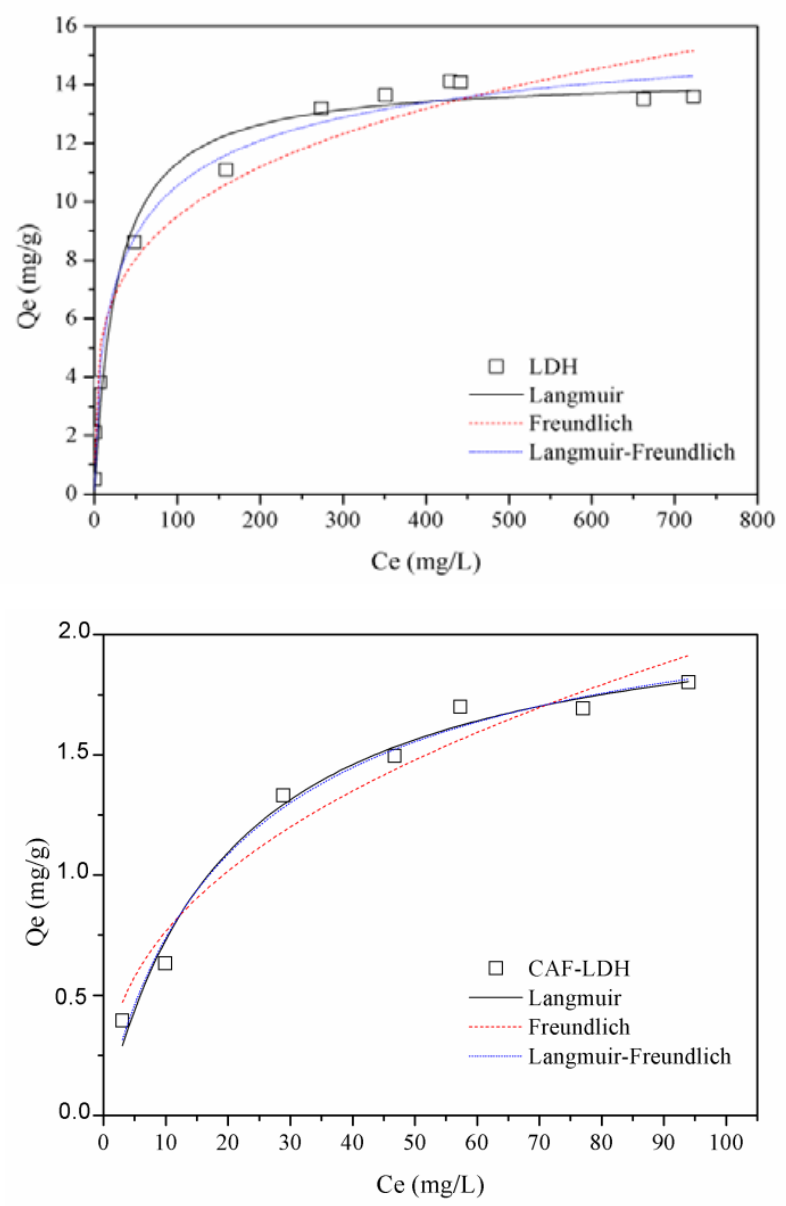

Among the isotherm models studied for $\mathrm{P}$ adsorption, the Langmuir-Freudlich model presented the best fit $\left(R^{2}>0.96\right)$ for all adsorbents studied. These results suggest phosphate adsorption occurred in heterogeneous surfaces making it possible to be controlled by several mechanisms. An important parameter to study the adsorption intensity between adsorbed molecules and adsorbent surface is $1 / n$. This parameter is divided into five levels that describe a higher or lower favoring of the adsorption phenomenon [52]. To lower the value of $1 / n$, or increase the value of $n$, adsorption is favored. Thus, results indicate more favorable adsorption of LDH-c compared to LDH, as well as of CAF-LDH-c in comparison to CAF-LDH. This phenomenon may be attributed to the capacity of structural reconstruction of LDH-c and to its greater superficial specific area
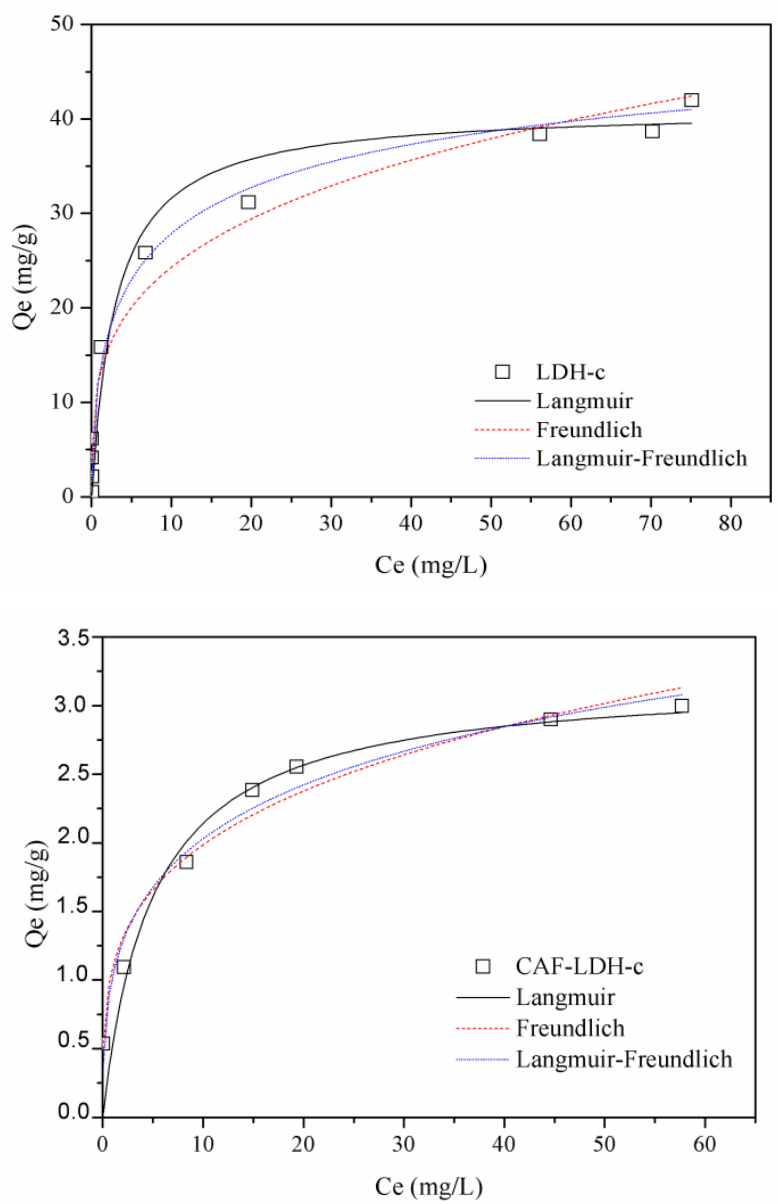

Fig. 6 Phosphate adsorption isotherms for LDH, LDH-c, CAF-LDH and CAF-LDH-c. 
Table 3 Phosphate adsorption isotherm according to the Langmuir, Freundlich and Langmuir-Freundlich models of LDH, LDH-c, CAF-LDH and CAF-LDH-c.

\begin{tabular}{llllllll}
\hline Model & Parameter & LDH & LDH-c & CAF-LDH & CAF-LDH-c & CAF-LDH* & CAF-LDH-c* \\
\hline \multirow{3}{*}{ Langmuir } & $K_{L}(\mathrm{~L} / \mathrm{mg})$ & 0.04 & 0.38 & 0.05 & 0.20 & - & - \\
& $Q_{m}(\mathrm{mg} / \mathrm{g})$ & 14.30 & 39.72 & 2.19 & 3.20 & 6.98 & 9.92 \\
\hline \multirow{3}{*}{ Freundlich } & $R^{2}$ & 0.97 & 0.96 & 0.98 & 0.93 & - & - \\
& $K_{F}\left((\mathrm{~L} / \mathrm{g})^{n}\right)$ & 3.19 & 12.88 & 0.30 & 1.09 & - & - \\
\hline \multirow{4}{*}{ Langmuir-Freundlich } & $n$ & 4.22 & 3.65 & 2.45 & 3.85 & - & - \\
& $R^{2}$ & 0.96 & 0.96 & 0.95 & 0.96 & - & - \\
\hline & $Q_{m}(\mathrm{~m} / \mathrm{mg})$ & 0.11 & 0.34 & 0.06 & 0.17 & - & - \\
& 17.18 & 51.75 & 2.31 & 6.98 & 7.36 & 21.63 \\
& $R^{2}$ & 1.73 & 1.87 & 1.09 & 2.67 & - & - \\
\hline
\end{tabular}

* values of $Q_{m}(\mathrm{mg} / \mathrm{g})$ related only to the mass of LDH and LDH-c present in CAF-LDH and CAF-LDH-c.

and pore volume [53, 54]. According to the division proposed by Tseng and $\mathrm{Wu}$ [52], the adsorption of LDH, LDH-c and CAF-LDH, are considered in a pseudo-linear level and CAF-LDH-c is considered at a favorable level of adsorption.

The maximum $\mathrm{P}$ adsorption capacity for $\mathrm{LDH}$, LDH-c, CAF-LDH and CAF-LDH-c according to the Langmuir-Freundlich model was 17.18, 51.75, 2.31 and $6.98 \mathrm{mg} / \mathrm{g}$ (Table 3). CAF did not have any significant phosphate adsorption values. For CAF-LDH and CAF-LDH-c, it is important to highlight these had lower phosphate adsorption values than those for LDH and LDH-c. This decrease occurs due to the lower amount of LDHs present in these films. Moreover, it is also necessary to take into consideration that not all LDH and LDH-c spread in the films are available for the adsorption process, as shown by SEM images. If only LDH and LDH-c powder mass were considered in CAF-LDH and CAF-LDH-c, the maximum $\mathrm{P}$ adsorption capacity is of $7.36 \mathrm{mg} / \mathrm{g}$ and $21.63 \mathrm{mg} / \mathrm{g}$. Therefore, LDH and LDH-c adsorb only 2.3 times and 2.4 times more phosphate than the respective films in $24 \mathrm{~h}$. Considering the CA:LDH ratio, the methodology presented in this work showed that the relationship of $3 \mathrm{~g}$ of CA and $1.5 \mathrm{~g}$ of LDH provide the double of $\mathrm{P}$ adsorption. In addition, this account does not consider the evaporation of acetone, which slightly increases the proportion of LDH in the film.
Materials produced with the objective of adsorbing $\mathrm{P}$ from wastewater are frequently reported in the literature. Some materials produced, called HAIX, DOW $2 \mathrm{~N}-\mathrm{Cu}$, DOW $3 \mathrm{~N}-\mathrm{Cu}$ and $\mathrm{CA}-\mathrm{Fe}$, have maximum $\mathrm{P}$ adsorption of 2.6, 1.1, 1.6 and $6.9 \mathrm{mg} / \mathrm{g}$ [55-57]. The maximum $P$ adsorption capacity obtained from isotherms for CAF-LDH-c indicates that this material could be used as an efficient adsorbent of $\mathrm{P}$ from wastewater or eutrophic waters. Furthermore, $\mathrm{CA}$ is recognized by the scientific community as a biodegradable polymer [58]. Thus, adsorption and biodegradability characteristics of the material produced indicate its possible use as a carbon source for the soil and also as source of phosphate fertilizer by the reuse of $\mathrm{P}$ from wastewater or eutrophicated water.

\section{Conclusions}

In this work, the following materials were prepared and characterized: LDH, LDH-c, CAF, CAF-LDH and CAF-LDH-c. The thickness, $\mathrm{A}_{\mathrm{H}_{2} \mathrm{O}}$ and stability in $\mathrm{H}_{2} \mathrm{O}$ of the produced films were evaluated, moreover, all of materials were subjected to phosphate adsorption. The formation of hybrid materials, CAF-LDH and CAF-LDH-c, increased film thickness, where CAF-LDH-c was thicker than CAF-LDH. CAF-LDH-c had higher $\mathrm{A}_{\mathrm{H}_{2} \mathrm{O}}$ than the other films, because of its increased thickness and mainly because of the $\mathrm{H}_{2} \mathrm{O}$ sorption process of these materials. $\mathrm{H}_{2} \mathrm{O}$ 
stability of $98.97 \%$ for CAF-LDH and $96.81 \%$ for CAF-LDH-c suggest the produced films can maintain their structural properties even after a long contact period with aqueous solutions. The maximum adsorption capacities of $\mathrm{P}$ for $\mathrm{LDH}, \mathrm{LDH}-\mathrm{c}$, CAF-HDL and CAF-LDH-c were 17.18, 51.75, 2.31 and $6.98 \mathrm{mg} / \mathrm{g}$. CAF did not have any significant $\mathrm{P}$ adsorption value. The maximum $\mathrm{P}$ capacity of CAF-LDH-c, along with its characteristics of biodegrability, thickness, $\mathrm{A}_{\mathrm{H}_{2} \mathrm{O}}$ and stability in $\mathrm{H}_{2} \mathrm{O}$, suggest the use of this material as a carbon source for the soil and also as a source of $\mathrm{P}$, by reusing $\mathrm{P}$ from wastewater and eutrophicated water.

\section{Acknowledgments}

This study was supported by the Fundação de Amparo à Pesquisa do Estado de Minas Gerais-FAPEMIG (APQ-00113-14), Rede Mineira de Química (RQ-MG)-Project: CEX-RED-00010-14 and Conselho Nacional de Desenvolvimento Científico e Tecnológico-CNPq (142338/2014-1, 312384/2013-0). The authors are also thankful to Fundação de Amparo à Pesquisa do Estado de São Paulo-FAPESP for the TG-DSC-MS facility. This study was financed in part by the Coordenação de Aperfeiçoamento de Pessoal de Nível Superior-Brasil (CAPES)-Finance Code 001.

\section{References}

[1] Novais, R. F., and Smyth T. J. 1999. Phosphorus in Soil and Plant in Tropical Conditions, 1st ed. UFV, Viçosa. (in Portuguese)

[2] Menezes-Blackburn, D., Zhang, H., Stutter, M., Giles, C. D., Darch, T., George, T. S., Shand, C., Lumsdon, D., Blackwell, M., Wearing, C., Cooper, P., Wendler, R., Brown, L., and Haygarth, P. M. 2016. "A Holistic Approach to Understanding the Desorption of Phosphorus in Soils." Environ. Sci. Technol. 50: 3371-81.

[3] Roy, E. D., Richards, P. D., Martinelli, L. A., Coletta, L. D., Lins, S. R. M., Vazquez, F. F., Willig, E., Spera, S. A., VanWey, L. K., and Porder, S. 2016. "The Phosphorus Cost of Agricultural Intensification in the Tropics." Nat Plants 2 (5): 16043.

[4] Withers, P. J. A., Rodrigues, M., Soltangheisi, A., De Carvalho, T. S., Guilherme, L. R. G., Benites, V. D. M., Gatiboni, L. C., De Sousa, D. M. G., Nunes, R. D. S.,
Rosolem, C. A., Andreote, F. D., Oliveira, A., De Coutinho, E. L. M., and Pavinato, P. S. 2018. "Transitions to Sustainable Management of Phosphorus in Brazilian Agriculture." Sci. Rep. 8: 1-13.

[5] Gómez-Romero, P., and Sanchez, C. 2004. Functional Hibrid Materials. 1st ed. New York: Wiley.

[6] Alcoutlabi, M., and Mckenna, G. B. 2005. "Effects of Confinement on Material Behaviour at the Nanometre Size Scale." Journal of Physics: Condensed Matter 17 (15): 461-524.

[7] Tronto, J., Cludia, A., Naal, Z., and Barros V. J. 2013. "Conducting Polymers/Layered Double Hydroxides Intercalated Nanocomposites." In Materials Science-Advanced Topics. London: IntechOpen.

[8] Mallakpour, S., and Dinari, M. 2016. "Bionanocomposite Materials from Layered Double Hydroxide/N-trimellitylimido-L-isoleucine Hybrid and Poly (Vinyl Alcohol): Structural and Morphological Study." J. Thermoplast. Compos. Mater. 29: 623-37.

[9] Totaro, G., Sisti, L., Celli, A., Aloisio, I., Di, G. D., Marek, A. A., Verney, V., and Leroux, F. 2018. "Dual Chain Extension Effect and Antibacterial Properties of Biomolecules Interleaved within LDH Dispersed into PBS by in Situ Polymerization." Dalt Trans. 47: 3155-65.

[10] Pearson, S., Pavlovic, M., Augé, T., Torregrossa, V., Szilagyi, I., D’Agosto, F., Lansalot, M., Bourgeat-Lami, E., and Prévot, V. 2018. "Controlling the Morphology of Film-Forming, Nanocomposite Latexes by RAFT Emulsion Polymerization." Macromolecules 51: 3953-66.

[11] Pearson, S., Pavlovic, M., Augé, T., Torregrossa, V., Szilagyi, I., D’Agosto, F., Lansalot, M., Bourgeat-Lami, E., and Prévot, V. 2017. "Nanocomposite Latexes Containing Layered Double Hydroxides: Via RAFT-Assisted Encapsulating Emulsion Polymerization.” Polym. Chem. 8: 1233-43.

[12] Sanchez, C., Belleville, P., Popall, M., and Nicole, L. 2011. "Applications of Advanced Hybrid Organic-Inorganic Nanomaterials: From Laboratory to Market." Chem. Soc. Rev. 40: 696.

[13] Benício, L. P. F., Silva, R. A., Lopes, J. A., Eulálio, D., dos Santos, R. M. M., De Aquino, L. A., Vergütz, L., Novais, R. F., Da Costa, L. M., Pinto, F. G., and Tronto, J. 2015. "Layered Double Hydroxides: Nanomaterials for Applications in Agriculture." Rev. Bras. Cienc. do Solo. 39: 1-13.

[14] Bernardo, M. P., Guimarães, G. G. F., Majaron, V. F., and Ribeiro, C. 2018. "Controlled Release of Phosphate from Layered Double Hydroxide Structures: Dynamics in Soil and Application as Smart Fertilizer." ACS Sustain. Chem. Eng. 6: 5152-61.

[15] Guo, Y., Wang, J., Li, D., Tang, P., Leroux, F., and Feng, Y. 2018. "Micrometer-Sized 
Dihydrogenphosphate-Intercalated Layered Double Hydroxides: Synthesis, Selective Infrared Absorption Properties and Applications as Agricultural Films." Dalt. Trans. 47: 3144-54.

[16] Benício, L. P. F., Constantino, V. R. L., Pinto, F. G., Vergütz, L., Tronto, J., and Costa, L. M. 2017. "Layered Double Hydroxides: New Technology in Phosphate Fertilizers Based on Nanostructured Materials." ACS Sustain. Chem. Eng. 5 (1): 399-409.

[17] Quintero, R. I., Galotto, M. J., Rodriguez, F., and Guarda, A. 2014. "Preparation and Characterization of Cellulose Acetate Butyrate/Organoclay Nanocomposites Produced by Extrusion.” Packag. Technol. Sci. 27: 495-507.

[18] Rodríguez, F. J., Galotto, M. J., Guarda, A., and Bruna, J. E. 2012. "Modification of Cellulose Acetate Films Using Nanofillers Based on Organoclays." J. Food Eng. 110: 262-8.

[19] Sabeti, D. F., Pakizeh, M., and Namvar-Mahboub, M. 2015. "Properties and Ultrafiltration Efficiency of Cellulose Acetate/Organically Modified Mt (CA/OMMt) Nanocomposite Membrane for Humic Acid Removal." Appl. Clay Sci. 105-106: 178-85.

[20] Nam, B. U., Min, K. D., and Son, Y. 2015. "Investigation of the Nanostructure, Thermal Stability and Mechanical Properties of Polylactic Acid/Cellulose Acetate Butyrate/Clay Nanocomposites." Mater. Lett. 150: 118-21.

[21] Santos, R. M. M., Gonçalves, R. G. L., Constantino, V. R. L., Santilli, C. V., Borges, P. D., Tronto, J., and Pinto, F. G. 2017. "Adsorption of Acid Yellow 42 Dye on Calcined Layered Double Hydroxide: Effect of Time, Concentration, $\mathrm{pH}$ and Temperature." Appl. Clay Sci. 140: 132-9.

[22] Santos, R. M. M., Tronto, J., Briois, V., and Santilli, C. V. 2017. "Thermal Decomposition and Recovery Properties of $\mathrm{ZnAl}-\mathrm{CO}_{3}$ Layered Double Hydroxide for Anionic Dye Adsorption: Insight into the Aggregative Nucleation and Growth Mechanism of the LDH Memory Effect." $J$. Mater. Chem. A 5: 9998-10009.

[23] Otoni, C. G., de Moura, M. R., Aouada, F. A., Camilloto, G. P., Cruz, R. S., Lorevice, M. V., de Soares, N. F. F., and Mattoso, L. H. C. 2014. "Antimicrobial and Physical-Mechanical Properties of Pectin/Papaya Puree/Cinnamaldehyde Nanoemulsion Edible Composite Films." Food Hydrocolloids 41: 188-94.

[24] Espitia, P. J. P., Soares, N. D. F. F., Teófilo, R. F., Dos Reis Coimbra, J. S., Vitor, D. M., Batista, R. A., Ferreira, S. O., De Andrade, N. J., and Medeiros, E. A. A. 2013. "Physical-Mechanical and Antimicrobial Properties of Nanocomposite Films with Pediocin and $\mathrm{ZnO}$ Nanoparticles." Carbohydrate Polymers 94 (1): 199-208.

[25] Sumari, S. M., Hamzah, Z., and Kantasamy, N. 2016.
"Adsorption of Anionic Dyes from Aqueous Solutions by Calcined and Uncalcined $\mathrm{Mg} / \mathrm{Al}$ Layered Double Hydroxide.” Malaysian J. Anal. Sci. 20 (4): 777-92.

[26] Ye, J., Cong, X., Zhang, P., Hoffmann, E., Zeng, G., Wu, Y., Zhang, H., and Fan, W. 2015. "Phosphate Adsorption onto Granular-Acid-Activated-Neutralized Red Mud: Parameter Optimization, Kinectis, Isotherms, and Mechanism Analysis." Water, Air and Soil Pollution 226: 306.

[27] Langmuir, I. 1918. "The Adsorption of Gases on Plane Surfaces of Glass, Mica and Platinum.” J. Am. Chem. Soc. 40: 1361-403.

[28] Freundlich, H. M. F. 1906. "Über Die Adsorption in Lösungen." Zeitschrift für Physikalische Chemie. A 57: 385-470.

[29] Fang, C., Zhang, T., Li, P., Jiang, R. F., and Wang, Y. C. 2014. "Application of Magnesium Modified Corn Biochar for Phosphorus Removal and Recovery from Swine Wastewater." International Journal of Environmental Research and Public Health 11 (9): 9217-37.

[30] Gómez-Fernández, S., Ugarte, L., Peña-Rodriguez, C., Zubitur, M., Corcuera, M. Á., and Eceiza, A. 2016. "Flexible Polyurethane Foam Nanocomposites with Modified Layered Double Hydroxides." Applied Clay Science 123: 109-20.

[31] Zhang, Q., Leroux, F., Tang, P., Li, D., and Feng, Y. 2018. "Low Molecular Weight Hindered Amine Light Stabilizers (HALS) Intercalated MgAl-Layered Double Hydroxides: Preparation and Anti-aging Performance in Polypropylene Nanocomposites." Polym. Degrad. Stab. 154: 55-61.

[32] Ma, X., Hu, C., Guo, R., Fang, X., Wu, H., and Jiang, Z. 2008. "HZSM5-Filled Cellulose Acetate Membranes for Pervaporation Separation of Methanol/MTBE Mixtures." Sep. Purif. Technol. 59 (1): 34-42.

[33] Castro, G. F., Ferreira, J. A., Eulálio, D., de Souza, S. J., Novais, S. V., Novais, R. F., Pinto, F. G., and Tronto, J. 2018. "Layered Double Hydroxides: Matrices for Storage and Source of Boron for Plant Growth." Clay Minerals 1-27.

[34] Roelofs, J. C. A. A., Van, B. J. A., Van, D. A. J., Geus, J. W., and Jong, K. P. 2002. "The Thermal Decomposition of Mg-A1 Hydrotalcites: Effects of Interlayer Anions and Characteristics of the Final Structure." Chemistry-A European Journal 8 (24): 5571-9.

[35] Zhu, Y., Zhu, R., Chen, Q., Laipan, M., Zhu, J., Xi, Y., and $\mathrm{He}, \mathrm{H}$. 2018. "Calcined Mg/Al Layered Double Hydroxides as Efficient Adsorbents for Polyhydroxy Fullerenes." Applied Clay Science 151: 66-72.

[36] Barud, H. S., Araújo Júnior, A. M., Santos, D. B., Assunção, R. M. N., Meireles, C. S., Cerqueira, D. A., 
Rodrigues, F. G., Ribeiro, C. A., Messaddeq, Y., and Ribeiro, S. J. L. 2008. "Thermal Behavior of Cellulose Acetate Produced from Homogeneous Acetylation of Bacterial Cellulose." Thermochimica Acta 471 (1-2): 61-9.

[37] Brum, S. S., Oliveira, L. C. A., Bianchi, M. L., Guerreiro, M. C., Oliveira, L. K., and Carvalho, K. T. G. 2012. "Synthesis of Cellulose Acetate from Bean Straw Using N-Bromosuccinimide (NBS) as a Catalyst." Polimeros. 22: 447-52. (in Portuguese)

[38] Hanna, A. A., Basta, A. H., El-Saied, H., and Abadir, I. F. 1999. "Thermal Properties of Cellulose Acetate and Its Complexes with Some Transition Metals." Polym. Degrad. Stab. 63 (2): 293-6.

[39] Soares, S., Camino, G., and Levchik, S. 1995. "Comparative Study of the Thermal Decomposition of Pure Cellulose and Pulp Paper." Polym. Degrad. Stab. 49: 275-83.

[40] Jain, R. K., Lal, K., and Bhatnagar, H. L. 1982. "A Kinetic Study of the Thermal Degradation of Cellulose and Its Derivatives." Macromolecular Chemistry and Physics 183 (12): 3003-17.

[41] Zhou, C. H., Zhang, D., Tong, D. S., Wu, L. M., Yu, W. H., and Ismadji, S. 2012. "Paper-Like Composites of Cellulose Acetate-Organo-Montmorillonite for Removal of Hazardous Anionic Dye in Water.” Chem. Eng. J. 209: 223-34.

[42] Ivánová, D., Albert, P., and Kavuličová, J. 2018. "Nitrate Removal from Model Aqueous Solutions and Real Water by Calcined Mg/Al Layered Double Hydroxides." Appl. Clay Sci. 152: 65-72.

[43] Wang, Q., Gao, Y., Luo, J., Zhong, Z., Borgna, A., Guo, Z., and O'Hare, D. 2013. "Synthesis of Nano-Sized Spherical $\mathrm{Mg}_{3} \mathrm{Al}-\mathrm{CO}_{3}$ Layered Double Hydroxide as a High-Temperature $\mathrm{CO}_{2}$ Adsorbent." RSC Advances 3 (10): 3414 .

[44] Alvarez, V. A., Ruseckaite, R. A., and Vázquez, A. 2007. "Aqueous Degradation of MATER BI Y-Sisal Fibers Biocomposites." Journal of Thermoplastic Composite Materials 20 (3): 291-303.

[45] Alvarez, V. A., Ruseckaite, R. A., and Vázquez, A. 2003. "Mechanical Properties and Water Absorption Behavior of Composites Made from a Biodegradable Matrix and Alkaline-Treated Sisal Fibers." Journal of Composite Materials 37 (17): 1575-88.

[46] Alvarez, V. A., and Vazquez, A. 2004. "Effect of Water Sorption on the Flexural Properties of a Fully Biodegradable Composite." Journal of Composite Materials 38: 1165-82.

[47] Bendinelli, E. V., Rocha, A. C., Barcia, O. E., Aoki, I. V., and Margarit-Mattos, I. C. P. 2016. "Effects of Lamellar Reconstruction Routes in the Release of Molybdate
Encapsulated in Mg-Al Layered Double Hydroxides." Materials Chemistry and Physics 173: 26-32.

[48] Bernardo, M. P., Moreira, F. K. V., Colnago, L. A., and Ribeiro, C. 2016. "Physico-Chemical Assessment of [Mg-Al-PO $]$-LDHs Obtained by Structural Reconstruction in High Concentration of Phosphate." Colloids and Surfaces A: Physicochemical and Engineering Aspects 497: 53-62.

[49] Cosano, D., Esquinas, C., Jiménez-Sanchidrián, C., and Ruiz, J. R. 2016. "Use of Raman Spectroscopy to Assess the Efficiency of MgAl Mixed Oxides in Removing Cyanide from Aqueous Solutions." Appl. Surf. Sci. 364: 428-33.

[50] Yao, Y., Gao, B., Chen, J., and Yang, L. 2013. "Engineered Biochar Reclaiming Phosphate from Aqueous Solutions: Mechanisms and Potential Application as a Slow-Release Fertilizer." Environ. Sci. Technol. 47: 8700-8.

[51] Jung, K. W., and Ahn, K. H. 2016. "Fabrication of Porosity-Enhanced $\mathrm{MgO} /$ Biochar for Removal of Phosphate from Aqueous Solution: Application of a Novel Combined Electrochemical Modification Method." Bioresource Technology 200: 1029-32.

[52] Tseng, R. L., and Wu, F. C. 2008. "Inferring the Favorable Adsorption Level and the Concurrent Multi-stage Process with the Freundlich Constant." Journal of Hazardous Materials 155 (1-2): 277-87.

[53] Constantino, V. R. L., and Pinnavaia, T. J. 1995. "Basic Properties of $\mathrm{Mg}^{2+}{ }_{(1-x)} \mathrm{Al}^{3+}{ }_{x}$ Layered Double Hydroxides Intercalated by Carbonate, Hydroxide, Chloride and Sulfate Anions." Inorg. Chem. 34: 883-92.

[54] Zhu, M. X., Li, Y. P., Xie, M., and Xin, H. Z. 2005. "Sorption of an Anionic Dye by Uncalcined and Calcined Layered Double Hydroxides: A Case Study." Journal of Hazardous Materials 120: 163-71.

[55] Henry, W. D., Zhao, D., SenGupta, A. K., and Lange, C. 2004. "Preparation and Characterization of a New Class of Polymeric Ligand Exchangers for Selective Removal of Trace Contaminants from Water." Reactive and Functional Polymers 60 (1): 109-20.

[56] Blaney, L. M., Cinar, S., and SenGupta, A. K. 2007. "Hybrid Anion Exchanger for Trace Phosphate Removal from Water and Wastewater." Water Research 41 (7): 1603-13.

[57] Wang, Z., Shi, M., Li, J., and Zheng, Z. 2014. "Influence of Moderate Pre-oxidation Treatment on the Physical, Chemical and Phosphate Adsorption Properties of Iron-Containing Activated Carbon." Journal of Environmental Sciences 26 (3): 519-28.

[58] Puls, J., Wilson, S. A., and Hölter, D. 2011. "Degradation of Cellulose Acetate-Based Materials: A Review." Journal of Polymers and the Environment 19 (1): 152-65. 